\title{
Commentary: Teaching Games of Understanding (TGfU) coaching effects on Heart Rate among Malaysian and Indian Junior Hockey Players
}

\author{
Sanmuga Nathan*
}

Sultan Idris Education University, Malaysia

\section{Article Info}

\section{Article Notes}

Received: August 27, 2018

Accepted: June 13, 2019

\section{${ }^{*}$ Correspondence:}

*Dr. Sanmuga Nathan, Universiti Pendidikan Sultan Idris, Tanjong Malim, Perak, Malaysia;

Email: sanmuga@fsskj.upsi.edu.my.

C 2019 Nathan S. This article is distributed under the terms of the Creative Commons Attribution 4.0 International License.

\section{Keywords}

TGfU

Skill-drill-Technical (SDT)

Heart-rate (HR) bpm

Small sided game play

Intensity

Warm up

Training effect

Recovery

\begin{abstract}
Teaching Games for Understanding (TGfU) offers tactical-technical instruction is gaining international recognition for its ability to produce intelligent players via a problem-solving approach in game play such as hockey. However the effect of TGfU pedagogical approach through small side game play (SSG) towards physiology components of Heart Rate (HR) still takes a backseat compared to research on tactical decision making and skill execution that has been studied widely. SSG proposed in TGfU approach dwells around duration of game play (load), how fast the SSG game manouvers (intensity) and players cardiovascular fitness can be detected by HR tool and therefore HR crucial to be investigated. This quasi-experimental study investigated the effect of TGfU compared to skill mastery instruction, termed as Skill Drill Technical (SDT), among Malaysian and Indian elite junior hockey players in terms of SSG game play intensity via heart rate (HR) measurement at different points of game play. A total of $n=60$ players with an average age of $15 \pm 1.03$ were selected via simple random technique from both countries involved in this study and assigned equally into groups, with 15 players per group for TGfU and for SDT across Malaysia and India. Gathered data were analysed using the ANOVA and ANCOVA techniques. There was significant higher warm-up HR bpm among players via TGfU compated to SDT across the two countries. Whereas HR bpm immediately after the 5 vs. 5 game play intervention and HR bpm after three minutes' recovery, Indian players with TGfU recorded a higher and significant difference compared to SDT. However, in contrast, findings indicated no significant difference between these two instruction models among Malaysian player. Therefore, overall findings reiterated that TGfU is a useful approach for game play to enhance intensity and cardiac output through $\mathrm{HR}$ bpm measurement. In conclusion, future research can employ together HR and RPM (Borg Scale) or electronic device for more accurate reading coupled 6 sec and $15 \mathrm{sec}$ HR readings. Future study, should too address the effect of TGfU on different variation of small sided game play intensity along skill execution and tactical decision making.
\end{abstract}

\section{Introduction}

Teaching Games for Understanding (TGfU) atactical-technical small sided game play (SSG) pedagogical learning model seems to be much sought-after in physical education and coaching contexts globaly ${ }^{1-3}$. While the traditional linear teaching pedagogical approach of skill mastery with structured skills-led teacher/coach centred approach termed as Skill-drill Technical (SDT) in this research still being practiced in some parts of the world based on situated and cultural learning background ${ }^{4-6}$. On the hand physiological components such as heart rate and $\mathrm{VO}_{2}$ max valuable tools used to asses game players cardiovascular fitness and intensity of training intervention. As for standard norm highest training intensity lies between $90 \%-100 \%$ of maximum HR bpm (171-180 bpm) for highest fitness performance. 
While moderate intensity fitness performance requires 8090\% maximum HR bpm (152-171 bpm) and lower intensity fitness only requires 70-80\% maximum HR bpm (133-152 $\mathrm{HR} \mathrm{bpm})^{7}$. Meanwhile a part from measuring main training intervention HR bpm, warming up HR bpm is crucial to optimize the perforamce, and the warming up HR bpm should hit around $65-85 \%$ maximum HR or $70-105 \mathrm{bpm}^{8}$. Moreover recovery HR bpm equally crucial in determining players fitness, a drops of HR $20 \mathrm{bpm}$ at first minutes after stopping of game play indicates players fitness are good. However in contrast if the HR bpm drop less than $12 \mathrm{bpm}$ indicating players are less fit.

Meanwhile research findings indicated small sided game play (SSG) of 3 vs.3 was able to elicited higher percentage $\%$ of HR compared offical match (OM) and 9 vs. 9 soccer game play ${ }^{9}$. Hence 3 vs. 3 small sided game play able to enhance higher intensity which crucial for higher fitness. However, very little practical application and research has been undertaken about the effect of pedagogical intervention on small sided game play (SSGs) intensity and fitness performance. Whereas full sided game play or SSG activities boils down time duration of game play (load) and how is fast the game being played being played depends on the intensity. The studies by ACSM indicated increase in V02 max and cardiac output dependents on intensity of activity ${ }^{10}$. However, again limited research has been undertaken to investigate both the TGfU and SDT pedagogical approaches effects the players game activity intensity. In contrast reasonable number of research has been conducted on TGfU in terms of tactical decision making and skill execution. TGfU emphasizes on SSG activity, while SDT involved structured skill teaching and the game play activities, therefore these kind of activities involves load (total volumes of activities) and how fast the players movements (intensity). Bascially increase in intensity of activity that can effect players cardiovascular fitness. Therefore activity intensity and duration of activity (load) crucial to be investigated through HR reading.

TGfU model evolved as a practical application of using six-step game based learning model through tacticaltechnical approach, as illustrated in Figure 1, evolved at Loughborough University in the late $1960 \mathrm{~s}^{4}$. Another TGfU version with some added elements of cue perception, skill drills and situated learning perspective was coined as the revised version of TGfU by Kirk and MacPhail as in Figure $2^{6}$. These two TGfU versions emphasises on tactical and skill elements of play. However, as to make TGfU as more holistic game play coaching approach, consideration should be given to HR bpm as a key index to control small sided game play (SSG) intensity.

TGfU is at the early stages of implementation in Physical Education (PE) curriculum and research perspective in Malaysia. On the other hand based on anecdotal findings

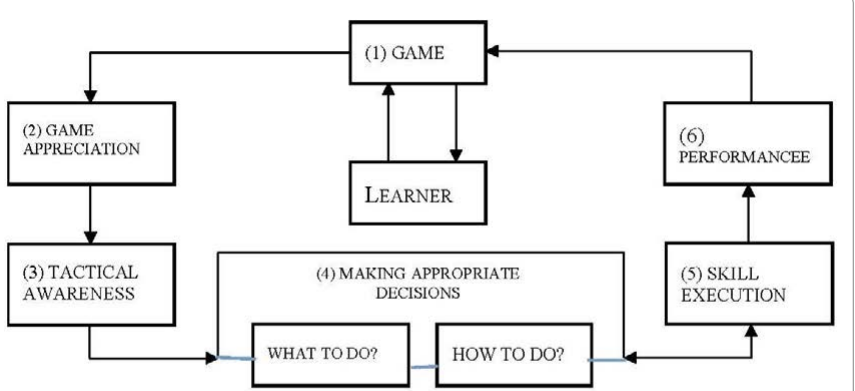

Figure 1. Original TGfU model, 1982 (with permission, Rod Thorpe).

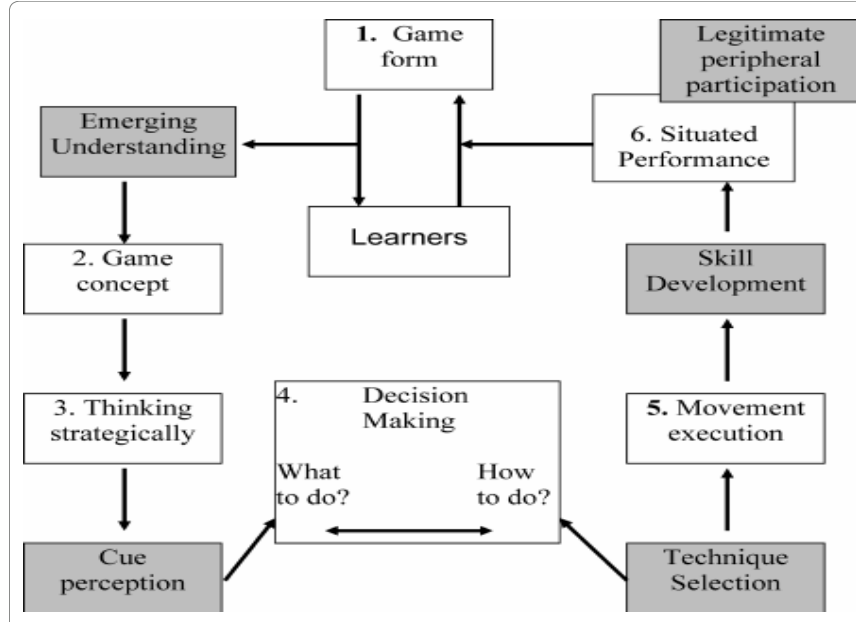

Figure 2. Revised TGfU, 2002 (with permission David Kirk).

and Google search of TGfU seems to be less known coaching approach and PE context in India. In addition, majority of coaches in Malaysia and India much prefer skill-based (SDT) coaching that gives importance to biomechanics principles and a motor learning teaching approach, whereby tactical elements of decision making and problem solving - the key tenets of TGfU taking backseat. Similarly, in the Indian coaching and teaching context of field hockey very much into skill-based technical model of SDT ${ }^{11}$. This similarity in skilled-based technical (SDT) approach in coaching context between Malaysia and India are probably due to a shared eastern tradition and cultural background as the eastern tradition values the coach or teacher (guru) as source of inspiration, knowledge in their endowers. In contrast as mentioned earlier, TGfU game approach model, which focuses mainly on tactical decision making and skill execution using small sided game play (SSG).

The game of hockey, whether field hockey or ice hockey, is characterized by a high volume of load, anaerobic intensity and cardiovascular fitness as well as the need for good recovery to optimize game-play performance ${ }^{5,14}$. Training volume and load are easily monitored via duration of time spent on activities such as small-sided game play, but intensity are much more difficult to assess ${ }^{15}$. Tools such as such as heart rate (HR), oxygen consumption, weight 
lifted, blood lactate and rate of athlete's perception of effort (RPE) during training allow researchers to measure training intensity ${ }^{8,12,13}$. Some studies investigate the HR measurement using small sided game play. Lang and Liu in their three month intervention of 4vs.4 game play among Beijing female youth soccer players improved their average HR of $177 \mathrm{~b} / \mathrm{min}$ and the maximum oxygen uptake of 94.81 $\mathrm{mL} / \mathrm{kg}^{16}$. These findings contrast to findings of Sell and Ledesma examined maximum heart rate (MHR) and energy expenditure using ten female field hockey players during competitive play using the Yo-Yo Intermittent Endurance test to determine maximum heart rate. No significant differences in MHR were observed between playing positions ${ }^{16}$.

Findings from Polish junior national ice-hockey players' playing intensity as low, moderate and high, based on their heart rates (HRs) recorded during a game using the maximum oxygen uptake test to determine intensity zones. Findings indicated the forwards spent more time in the low-intensity zone than the defence men ${ }^{17}$. Another study by Cherappurath and Kabeer investigated football and handball players $(n=30$ players, aged 19-22). Findings indicated no significant difference in resting pulse rate between soccer players and handball players ${ }^{18}$.

Drawing from various studies as discussed above research, intensity, aerobic and anaerobic metabolism during small sided game play can be linked to HR bpm reading. Therefore small-sided game play, as proposed in TGfU, significantly contributes to higher cardiac intensity, and therefore coaches should monitor this closely via heart rate (HR) as it's important tools in coaching game such as field hockey via TGfU. In hockey, to date, limited research has been conducted examining the intensity and cardiac output of small-side game play advocated pedagogical TGfU in practical game play application ${ }^{4,9,19}$.

Eventhough HR crucial in sports and game coaching, limited study has been undertaken to investigate the effect of TGfU via mini or small-sided game-play intensity evaluated using the crucial HR tool. Furthermore limited research has been conducted to investigate the effect of pedagogical model such as TGfU compared the traditional skill based approach known as Skill-Drill Technical (SDT) in terms small sided game players HR, what more camparison across different countries and settings.

\section{The effect of TGfU, Skill-Drill Technical Pedagogical on Cardiovascular Fitness}

The present research employed a balanced sample experimental design with a pre-and post-test control group design investigated the effects of pedagogical model of TGfU and the traditional skill based approach known as Skill-Drill Technical (SDT) in coaching context that was tested across Malaysia and India in hockey game coaching environment. The effectiveness these two pedagogical approaches was assessed and evaluated in terms HR beats/ intensity before, immediately after and after three minutes' recovery of 5 vs. 5 small sided field hockey game play. This was compared among Malaysian and Indian junior elite hockey players before and after training intervention.

\section{Methodology}

The participants of this study comprised the junior hockey players were recruited systematically who were representative of the limited population that were available across the two countries. Participants concerned were granted through their coaching academics in India and the Malaysian Education Ministry that control the Sports School in Malaysia, all participants safety were taken care of. In each countries 30 players were selected randomly, in line with Cohen's sampling power of .80 and furthermore in complying with statistically analysis sample requirement of each cell minimum requires only 15 samples.

The Malaysian sample consists of $n=30$ sports school players, aged 15 years \pm 1.0 , who were selected randomly out of a total of $n=45$ players; using only 30 in this sample was a limitation of this study. This sample was assigned and distributed equally into groups of TGfU, $n=15$ and SDT model, $n=15$. As for the Indian players, they also comprised a sample of $n=30$ players out of a possible 60 from Indian academic junior hockey players (aged 14-16 \pm 2.0 years old), who were selected randomly using the simple random sampling technique and assigned equally into groups of TGfU, $n=15$ and control group SDT, $\mathrm{n}=15$.

\section{Measurements}

This research, employed radial HR bpm to measure intensity at different points of small-sided hockey game play. The most popular post-exercise pulse palpation utilized radial (wrist) heart rate measurement for $6 \mathrm{~s}$ (number HB in $6 \mathrm{~s} \times 10$ to get HR beatsmins-1 because it is relatively easy and requires no equipment ${ }^{21}$. In this research, to measure HR or pulse rate, the Wrist Radial palpitation method was used to take the pulse at three different point intervals in order to measure HR before (warm-up HR) and after small-sided game play of 5 vs. 5, and another HR was collected after 3 min of game play to determine recovery HR. In detail, the following interval HRs were measured: (a) before small-sided game play of 5 vs. 5 , (b) immediately after 5 vs. 5 small game play, and (c) final interval HR (recovery HR) after 3 min of 5 vs. 5 smallsided game play to detect the rate of players' recovery at pretest and post-test. The pulse was taken for $10 \mathrm{~s} \times 6$ for three times to get average pulse rate for 1-min pulse rate reading. Meanwhile, participants were given three trials of HR measurement before the actual study to make them comfortable with the radial palpation technique. 


\section{Pedagogical Models Intervention}

The selected players in the TGfU and SDT intervention groups underwent three (3) specific training activities based two models instructions two sessions per week for two (2) hour for five weeks consecutively as training load. Both groups in Malaysia and India followed similar activities in terms of training volume ( 2 hours per session), intensity (low intensity at 120-140 HR, medium intensity at 130-150 HR and high intensity at 150-170 HR) based Karvonen HRR (Heart Rate Reserve) formula light intensity of 30\%-40\%, 40\%-60\% moderate intensity and vigorous intensity $60 \%-90 \%{ }^{19}$. As for rest, active recovery of three (3) minutes were given from one activity to another activity. The TGfU group predominantly trained their tactics, skills, fitness and physical conditioning components via smallsided game situations. Game play were the main coaching activities to improve their related game-play skills, while tactical thinking and solving game-related strategies of attacking and defending in game were discussed and applied in game play situations. Briefly, the TGfU coaching process encourages the players to discuss and think by answering questions and solving game-play problems through practical application. Questions are based on 'what to do' and 'how to do' in terms of manipulating tactics and proper skill execution in game play. The TGfU approach helps the players to decide on applying appropriate tactics and skills in small-sided game situations and activities ${ }^{4,22}$. On the other hand, SDT coaching underpinned linear instruction conducted by coaches, were in terms of volume and intensity activities as well rest is similar to the TGfU approach. However the SDT focuses on skill teaching skill drills activities feedback and skill mastery as the main content of coaching. Players were also given some form of game play, either small-sided game play or full game play, allocated at the end of each coaching unit. The implementation of these two intervention models periodized based on sports training principles and motor learning principles ${ }^{13,23}$

\section{Data Collection and Analysis}

As HR responds to warm-up rate, after mini-game activities and recovery HR, pre- and post-tests were calculated based on total number of pulses per minute. Pretest data was screened for normality using the KolmogorovSmirnov and Shapiro-Wilk tests for all dependent variables; the findings of both tests indicated no significant difference with $p>0.05$, hence, normality of data prevailed. Data from all the dependent variables from pre-test and post-test were analysed through ANOVA using SPSS software version 21. Furthermore, the inferential statistic of ANCOVA was employed to confirm the results when significant difference was yielded at the pre-test level.

\section{Results}

The following statistical results were recorded as in Table 1, for Malaysian players in term of HR. For pre-test, warm-up HR before intervention indicated no significant difference between players in TGfU $(82.07 \pm 4.46)$ and SDT $(84.1 \pm 4.04), F(1,28)=1.65, p>0.05$. In contrast, the posttest result for warm-up HR before small-sided game play indicated a significant difference between TGfU (78.86 \pm $2.87)$ and SDT $(77.60 \pm 3.45), F(1,28)=5.27, p<0.05$. Pretest HR immediately after small-sided 5 vs. 5 game play indicated no significant difference between TGfU (135.20 $\pm 6.70)$ and SDT $(130.60 \pm 4.11), F(1,28)=0.220, p>0.05$. Post-test HR immediately after small-sided 5 vs. 5 game play also revealed no significant difference between TGfU $(126.26 \pm 5.68)$ and SDT (128.20 \pm 5.44$)$ among Malaysian players, $F(1,28)=1.87, p>0.05$. For recovery HR after three minutes, pre-test results indicated no significant difference between TGfU (82.46 \pm 4.45$)$ and SDT $(83.20 \pm 4.10)$ among Malaysian players $F(1,28)=0.906, p>0.05$. Post-test results for HR after three minutes also indicated no significant difference between the TGfU $(79.33 \pm 4.20)$ and SDT $(80.13$ \pm 4.58 ) pedagogical models, $F(1,28)=0.906, p>0.05$.

The following results were recorded for Indian hockey players as in Table 2, in terms of HR findings. The pre-test warm-up HR before the intervention phase indicated no significant difference between players in TGfU (83.80 \pm 6.96) and SDT $(84.26 \pm 3.61), F(1,28)=0.053, p>0.05$. However, the post-test result for warm-up HR indicated significant difference detected between TGfU (82.66 \pm $6.21)$ and SDT $(77.86 \pm 3.22), F(1,28)=7.04, p<0.05$. For pre-test HR, immediately after 5 vs. 5 game play indicated significant difference between TGfU $(134.80 \pm 5.78)$ and SDT $(128.40 \pm 4.48), F(1,28)=11.46, p<0.05$. Post-test HR immediately after 5 vs. 5 small-sided game play revealed significant difference between TGfU $(136.73 \pm 5.68)$ and SDT $(130.60 \pm 4.11)$ among Indian players, $F(1,28)=8.80$, $p<0.05$. Therefore, to confirm this result, ANCOVA analysis

Table 1. HR (Mean/SD) for phases of activities for Malaysian junior players.

\begin{tabular}{|l|c|c|}
\hline \multicolumn{1}{|c|}{ Model/Phase } & TGfU & SDT \\
\hline Pre-test warm-up HR before game play & $82.07 \pm 4.46$ & $84.1 \pm 4.04$ \\
\hline Post-test warm-up HR before game play & $78.86 \pm 2.87$ & $77.60 \pm 3.45$ \\
\hline Pre-test HR immediately after game play & $135.20 \pm 6.70$ & $130.60 \pm 4.11$ \\
\hline Post-test HR immediately after game play & $126.26 \pm 5.68$ & $F(1,28)=0.220, p>0.05$ \\
\hline Pre-test HR after 3 min recovery game play & $82.46 \pm 4.45$ & $128.20 \pm 5.44$ \\
\hline Post-test HR after 3 min recovery game play & $79.33 \pm 4.20$ & $83.20 \pm 4.10$ \\
\hline
\end{tabular}


Table 2. HR (M/SD) phase of activities for Indian junior players.

\begin{tabular}{|l|c|c|c|}
\hline \multicolumn{1}{|c|}{ Model/Phase } & TGfU & SDT & Significant \\
\hline Pre-test warm-up HR before game play & $83.80 \pm 6.96$ & $84.26 \pm 3.61$ & $F(1,28)=0.053, p>0.05$ \\
\hline Post-test warm-up HR before game play & $82.66 \pm 6.21$ & $77.86 \pm 3.22$ & $F(1,28)=7.04, p<0.05$ \\
\hline Pre-test immediately game play & $134.80 \pm 5.78$ & $128.40 \pm 4.48$ & $F(1,28)=11.46, p<0.05$ \\
\hline Post-test immediately game play & $136.73 \pm 5.68$ & $130.60 \pm 4.11$ & $F(1,28)=8.80, p<0.05$ \\
\hline Pre-test after 3 min recovery game play & $87.00 \pm 5.35$ & $85.06 \pm 4.09$ & $F(1,28)=1.22, p>0.05$ \\
\hline Post-test after 3 min recovery game play & $100.53 \pm 4.38$ & $95.73 \pm 6.95$ & $F(1,28)=5.11, p<0.05$ \\
\hline
\end{tabular}

Table 3. Analyses of covariance summary for HR immediately after 5 vs. 5 game play.

\begin{tabular}{|c|c|c|c|c|c|}
\hline Source & Sum of Square & df & Mean Square & F & Sig \\
\hline Group & 128.183 & 1 & 128.183 & 7.98 & 0.10 \\
\hline
\end{tabular}

Table 4. Estimated marginal means for immediately after 5 vs. 5 game play.

\begin{tabular}{|l|l|l|l|l|}
\hline \multirow{2}{*}{ Programme } & Mean & SE & \multicolumn{2}{|c|}{ 95\% Confidence Interval } \\
\cline { 4 - 5 } & & Lower Bound & Upper Bound \\
\hline TGfU & $133.97^{\text {a }}$ & 1.40 & 131.00 & 136.84 \\
\hline SDT & $129.22^{\text {a }}$ & 1.40 & 126.35 & 132.100 \\
\hline
\end{tabular}

a Covariates appearing in the model are evaluated at the following values: game play $=133.30$.

was carried out as stipulated in Tables 3 and 4, and the findings confirmed that there was a significant difference between these two models after intervention in terms of HR immediately after 5 vs. 5 game play. The covariate analysis (ANCOVA) result, indicated significant difference between these two models immediately after game play, $\mathrm{F}(1,27)=5.05 \mathrm{p}<0.05$ as in Table 3 and the estimated marginal means for HR immediately after play at posttest are presented in Table 4. For recovery HR after three minutes of 5 vs. 5 small-sided game play, pre-test results indicated no significant difference between TGfU (87.00 $\pm 5.35)$ and SDT $(85.06 \pm 4.09)$ among Indian players $F(1,28)=1.22, p>0.05$. However, post-test results for HR after three minutes of 5 vs. 5 small-sided game play results indicated significant difference between the TGfU $(100.53$ $\pm 4.38)$ and SDT $(95.73 \pm 6.95)$ pedagogical models, $F(1,28)$ $=5.11, p<0.05$.

\section{Discussion and Implication}

As for pre-test warm-up intensity, HR bpm indicated no significant difference between the TGfU and SDT models among players in both Malaysia and India, as TGfU and SDT both recorded a higher warm-up HR bpm, probably due to low levels of fitness. There was a slightly lower significance difference between the two models in terms of mean HR $\mathrm{bpm}$ in both countries at post-test mean warm-up HR bpm. However, the TGfU model recorded significantly higher warm-up HR bpm (Malaysia: 78.86 bpm; India: 82.60 bpm) compared to SDT in both countries after intervention which within the recommended norm of warm up 65$85 \%$ maximum HR or $70-105 \mathrm{bpm}^{8}$. This was probably due to game based warm up activities manipulated by
TGfU approach compared SDT which utilized structured warming up with 3-4 jogging, static stretching and dynamic warming up activities in both countries. Therefore game led warm up activities underpins TGfU trigger higher intensity and increase $\mathrm{HR}$ bpm at warming up stage.

Next, findings for HR bpm immediately after smallsided 5 vs. 5 game play at post-test indicated a significant difference between these two instructional models only for Indian players using TGfU (136.73 \pm 5.68$)$ compared to Malaysian players with a higher HR bpm. The effect of TGfU training approach enable the Indian players to hit moderate intensity fitness within standard norm of 130-152 bpm, whereas Malaysian players played in lower intensity fitness with TGfU and SDT models ${ }^{7}$. This was probably due to style of Indian hockey playing that utilize dribbling and stickwork strenuous workout compared to Malaysian players more hitting and passing approach and limited higher intensity of movement even when using the TGfU approach. The present findings the effect of TGfU among India players are similar to findings by Asci, which indicated that 3 vs. 3 game play recorded higher HR and \% HR max compared to 9-a-side game play 9 . The findings for Indian players in this research are in line with the findings of Ghosh, Goswami, Mazumdar, and Mathur, whose study indicated that junior hockey players' ( $n=25 ; 18 \pm 0.6$ years) mean heart rate during a full hockey match was $143.4 \mathrm{bpm}^{19,24}$. Therefore, the TGfU model, through small-sided game play, maximized physiological adaptations especially for Indian hockey through small sided game play, hence similar to distance runners' exercise programmes ${ }^{25,26}$.

These findings were less similar to findings by Capranica and associates, who found HR bpm values exceeding 170 beatsmin $^{-1}$ represent high-intensity work activities $^{27}$. If this is the case, then the present research HR bpm results suggest that the young players participating in both small-sided games should work at higher levels of intensity. Again the present HR bpm findings in this study after intervention recorded lower HR bpm compared to findings of Clemente \& Rocha ${ }^{28}$, who recorded higher HR at two phases of 2 vs. 2 small-sided game play ( 171 beats $/ \mathrm{min}$ and 177 beats/min), while 4 vs. 4 recorded 159 beats/min and 167 beats/min. However, the present findings revealed that Indian players recorded higher HR bpm compared to the Malaysian players in small-sided game play. 
Post-test results for Malaysian players after three minutes' recovery recorded lower HR bpm using TGfU $(79.33 \pm 4.20)$ and SDT $(80.13 \pm 4.58)$ compared to HR bpm immediately after game play. On the other hand, the Indian players' recovery HR bpm also indicated reduced HR compared to HR immediately after game play. However, Indian player recovery HR recorded higher HR bpm for the TGfU group $(100.53 \pm 4.38)$ and the SDT $(95.73 \pm 6.95)$ compared to Malaysian players' recovery HR bpm. These results indicated moderate positive recovery as there was at least $20 \mathrm{HR}$ bpm drop at all these models across two countries, however to achieve highest fitness level HR bpm should drop to $60 \%-70 \%$ maximum HR bpm.

These findings indicate that younger players tolerate moderate HR bpm reading during the recovery period after a small-sided game of 5 vs. 5 among both Malaysian and Indian hockey players. The present findings illustrated that the TGfU style of game play increased HR bpm findings among both Malaysian and Indian players, which is important for blood circulation and improving players' physiological systems. However, this research findings indicates that Indian players are able to increase their HR bpm during game play and are slower in recovery compared to Malaysian players due to tradition and background style of playing, especially with the Indian players employing dribble and stick-work techniques movement skills and bll control in small-sided game play. In contrast, Malaysian players utilize hit-and-run playing tactics that do not increase game play intensity and recovery HR bpm drop faster. However, based on Indian players' style of playing, there was significant influence and support for higher fitness level through HR bpm measures for TGfU that emphases small-sided game play being able to submaximize game-play intensity. The present findings similar with findings by Castellano and associates ${ }^{29}$. Futhermore the present findings are in line with findings by Mclean and associates, who indicated that number of players in small-sided game play and game format do influence physiological and physical intensity demands differently, hence HR bpm was affected by this influence ${ }^{9,30}$.

\section{Conclusions}

Findings for post-test warm-up intensity HR bpm performances indicated significant difference between these two models with TGfU recorded higher HR bpm across players in two countries. For HR bpm immediately after 5 vs. 5 small sided game intervention and HR bpm after three minutes' recovery, findings among Indian players indicated a significant difference between the two pedagogical models compared to Malaysian players. Based on the present findings, TGfU, through small-sided game play, is able to enhance intensity and cardiac output of the players during game play based Indian players findings. Future research should address the importance of monitoring the effect of pedagogical model such as TGfU in terms of other small sided game variation to measure the game play intensity. In order to accurately measure game play intensity, future research can employ both HR bpm or RPE with Borg Scale. As overall pedagogical models of coaching do influence physiological and physical attributes such as intensity and volume of any game play, especially in negotiating smallsided game play. In conclusion, in order for TGfU to be more relevant for future research, TGfU proponents ought to address linking game play attributes such as skill execution, tactical decision making with physiological parameters. Although this study employed radial heart rate and future study should use more advance electronic HR bpm device for more accurate reading, determining other physiological and biochemical measurement as to examine at pre-and post-exercise variation of small sided game play through TGfU model across different category game play.

\section{Acknowledgments}

The study has been supported by a small grant from the Sultan Idris Education University of Malaysia (20110036-107-01). The writer acknowledges the support of the Education Ministry of Malaysia (KP(BPPDP) 603/5/JLD.9, 52 ) in allowing the use of sports school players, as well as Prof. Gl Khanna of Manav Rachna International University, India, and the Indian hockey coaches (Dr. Ajay Bansal, Mr. Joshi, Ms. Durga and Mr. Kaushik as well as Mr. Amirul of SMMI Sports School of Malaysia.) for giving logistic support to materialize researching Indian hockey players. The write acknowledges to TGfU-SIG colleagues Dr. Thorpe, Prof. Steve Mitchell, Prof. David Kirk, Prof. Adrian Turner and appreciate their kind permission in using and adapting their models and instruments.

\section{Conflicts of Interest}

The authors declare no conflict of interest.

\section{References}

1. Grehaigne JF, Godbout P, Bouthier D. The teaching and learning of decision making in team sports. Quest. 2001; 53: 59-75.

2. Memmert D, Baker J, Bertsch C. Play and practice in the development of sport-specific creativity in team sports. High Abil Stud. 2010; 21. do i:10.1080/13598139.2010.488083.

3. Metzler M. Implications of models-based instruction for research on teaching: A focus on teaching games for understanding. In Teaching Games for Understanding: Theory, Research, and Practice; Griffin, L.L., Butler, J.I., Eds.; Human Kinetics: Champaign, IL, USA, 2005.

4. Bunker D, Thorpe R. A model for the teaching of games in secondary schools. Bull Phys Educ. 1982; 18: 5-8.

5. Montgomery DL. Physiological profile of professional hockey players-A longitudinal study. Appl Physiol Nutr Metab. 2006; 31: 181-185.

6. Kirk D, MacPhail A. Teaching games for understanding and situated learning: Rethinking the Bunker-Thorpe model. J Teach Phys Educ. 2002; 21: 177-192.

7. Dysck F. Seminar fitness Tuesday: Using heart rate as a fitness guide. YMCA Saskatoon. 2016. 
8. Dijk H, Megan RV. The secret of running: Maximum performance gains through effective power metering and training analysis. Meyer \& Meyer Sport. 2017.

9. Asci A. Heart rate responses during small sided games and offical match play in soccer. Sports MDPI. 2016; 1-7.

10. John D, Sterza G, Swensen T. Monitoring exercise heart rate using manual palpitation. ACSM Health Fit J. 2007; 11: 1-4.

11. Hopper T. Teaching games for understanding: The importance of student emphasis over content emphasis. J Health Phys Educ Recreat Dance. 2002; 73: 44-48.

12. .Fitts PM, Posner MI. Human Performance; Brooks and Cole Publishing: Belmont, CA, USA. 1967.

13. Shaw I, Shaw B. Differences in maximum heart rates in distance runners during training competition and laboratory testing. In Proceedings of the XIV Commonwealth International Sports Science Congress, Manav Rachana International University, Faridabad, India, 27-30 September, 2010

14. Lythe J, Kilding AE. Physical Demands and Physiological Responses during Elite Field Hockey. Int J Sports Med. 2011; 32: 523-528.

15. Coutts A, Wallace L, Slattery K. Monitoring training load. Sports Coach. 2004; 27: 1-4.

16. Lang J, Liu Y. 4 to 4 game training method for women's football player physical ability influence. Shenyang Sports Coll J. 2010; 3: 122-125.

17. Stanula A, Roczniok R. Game intensity analysis of elite adolescent ice hockey players. J Hum Kinet. 2014; 44: 211-221.

18. Cherappurath N, Kabeer DA. Comparative study on selected physiological variables between football and handball players. Int Recent Sci Res. 2015; 6: 6095-6097.
19. Ignaszeki, Lau B, Wong S, et al. The Science of exercise perscreption: Marti Karvonen and his contributions. BCMJ. 2017; 59(1): 38-41.

20. Cohen J. Statistical power analysis for the behavioral sciences. Second Edition. Hillsdale, NJ: Lawrence Erlbaum Associates, Publishers. 1998.

21. Jeukendrup A, Diemen AV. Heart rate monitoring during training and competition in cyclists. J Sports Sci. 1998; 16 (Suppl. 1): 91-99.

22. Mitchell SA, Oslin JL, Griffin LL. Teaching Sport Concepts and Skills: A Tactical Games Approach; Human Kinetics: Champaign, IL, USA, 2005.

23. Bompa T. Periodization: Theory and Methodology of Training; Human Kinetic: Champaign, IL, USA, 1999.

24. Ghosh AK. Heart rate and blood lactate responses during execution of some specific strokes in badminton drills. Int J Appl Sports Sci. 2008; 20: 27-36.

25. Beachle TR, Earle RW. Essentials of Strength Training and Conditioning, 2nd ed.; Human Kinetics: Champaign, IL, USA, 2000.

26. Clemente F, Rocha R, Martins F, et al. Acute effects of different formats of small-sided and conditioned handball games on heart rate responses in female students during PE classes. Sports. 2014; 2: 51-58.

27. Capranica L, Tessitore A, Guidetti L, et al. Heart rate and match analysis in pre-pubescent soccer players. J Sports Sci. 2001; 19: 379-384.

28. Clemente F, Rocha R. The effects of task constraints on the heart rate responses of students during small-sided handball games. Kinesiol Slov. 2012; 18: 27-35.

29. Castellano J, Casamichana D, Dellalj A. Influence of game format and number of players on heart rate responses and physical demands in small-sided soccer games. J Strength Cond Res. 2013; 27: 1295-1303.

30. McLean S, Kerhervé H, Naughton $M$, et al. The Effect of recovery duration on technical proficiency during small-sided games of football. Sports. 2016; 4: 39. 